\title{
COMPARATIVE STUDY OF SHORT TERM VS. LONG TERM USE OF PROPHYLACTIC ANTIBIOTICS IN LOWER SEGMENT CAESAREAN SECTION
}

\author{
Subha Sivagami Sengodan', Mohana Dhanapal2, Vijaya Subramanian³, Mohanambal4 \\ ${ }^{1}$ Senior Assistant Professor, Department of Obstetrics \& Gynaecology, Dr. MGR Medical University, Chennai. \\ ${ }^{2}$ Senior Assistant Professor, Department of Obstetrics \& Gynaecology, Dr. MGR Medical University, Chennai. \\ ${ }^{3}$ Associate Professor, Department of Obstetrics \& Gynaecology, Dr. MGR Medical University, Chennai. \\ ${ }^{4}$ Professor, Department of Obstetrics \& Gynaecology, Dr. MGR Medical University, Chennai.
}

\section{ABSTRACT}

\section{BACKGROUND}

A large number of randomized trials have demonstrated that a single dose of an antimicrobial agent at the time of caesarean section will serve to decrease the infectious morbidity significantly in high risk labouring patients as well as those undergoing caesarean section. In the present prospective study, antibiotic prophylaxis with single dose ceftriaxone $1 \mathrm{gm}$ IV administered after umbilical cord clamping in caesarean section is very safe, cost effective, more convenient and also effective in reducing maternal morbidity and post-operative hospital stay when compared to traditional use of ampicillin/gentamicin in caesarean section.

\section{MATERIAL AND METHODS}

Prospective study carried out in the Department of Obstetrics and Gynaecology, Government RSRM lying in hospital and Stanley Medical College Chennai from June 2007 to October 2008 that involved 1000 pregnant women undergone lower segment caesarean section who were divided into two groups randomly after excluding the exclusion criteria.

\section{RESULTS}

Single dose ceftriaxone prophylaxis is cost effective, in that the cost of treatment is 4 times less than that of conventional antibiotics, ampicillin/gentamicin. Ceftriaxone prophylaxis safe, effective, convenient and saves man power thus preventing irregularity in administering drugs and can easily replace the 5 days' extended use of antibiotics.

\section{CONCLUSION}

In the present study antibiotic prophylaxis with single dose ceftriaxone $1 \mathrm{gm}$ IV administered after umbilical cord clamping in caesarean section is very safe, cost effective, more convenient and also effective in reducing maternal morbidity and post-operative hospital stay when compared to traditional use of ampicillin/gentamicin in caesarean section.

\section{KEYWORDS}

Antibiotic Prophylaxis, Lower Segment Caesarean Section, Infections.

HOW TO CITE THIS ARTICLE: Sengodan SS, Dhanapal M, Subramanian V, et al. Comparative study of short term vs. long term use of prophylactic antibiotics in lower segment caesarean section. J. Evolution Med. Dent. Sci. 2016;5(28):1445-1448,

DOI: $10.14260 /$ jemds/2016/339

\section{INTRODUCTION}

Prophylactic antibiotics in surgery is intended to prevent morbidity and mortality as well as to reduce the duration and the cost of hospitalization.(1) Despite the advent of antibiotic, infection in obstetric practice continue to cause problems, particularly the developing countries. The source of wound infection and genital tract infection after caesarean section is primarily due to organisms from the patient's abdominal skin introduced during or after the incision and bacteria ascending from the vagina before or after the operation.(2)(3)(4) The infection could be due to cross infection. Ceftriaxone is the third generation cephalosporin of choice due to its longer duration of action. It has an action on aerobic gram negative bacteria as well as gram positive bacteria. The present study was carried out to evaluate the efficacy and safety of ceftriaxone in caesarean section.

Financial or Other, Competing Interest: None.

Submission 18-02-2016, Peer Review 12-03-2016,

Acceptance 19-03-2016, Published 07-04-2016.

Corresponding Author:

Dr. Subha Sivagami Sengodan,

GF 2, Sriram Aravind Apts.,

356/218, Avvai Shanmugam Salai,

Gopalapuram, Chennai-600086.

E-mail: drppsamysubha@gmail.com

DOI: $10.14260 /$ jemds/2016/339

\section{AIM OF THE STUDY}

1. To assess the effectiveness of single dose antibiotic prophylaxis with Inj. Ceftriaxone $1 \mathrm{gm} \mathrm{IV} \mathrm{after} \mathrm{clamping}$ the umbilical cord in controlling infections in caesarean section.

2. To reduce the total requirement of antibiotics in lower segment caesarean section cases to reduce the cost of treatment.

3. To compare the effectiveness of ceftriaxone with ampicillin and gentamicin combination, which is being presently used for 5 days postoperatively.

\section{MATERIALS AND METHODS OF STUDY}

This is a prospective study carried out in the Department of Obstetrics and Gynaecology, Government RSRM lying in hospital and Stanley Medical College Chennai from June 2007 to October 2008 that involved 1000 cases undergone lower segment caesarean section who were divided into two groups randomly after excluding the exclusion criteria.

\section{The Exclusion Criteria}

1. Hypersensitivity to cephalosporins.

2. Pre-existing infection.

3. Concomitant systemic disease such as uncontrolled diabetes, hypertension, renal or hepatic disease.

4. PROM.

5. Patients on pre-treatment with other antibiotics. 
6. Patients with asthma, anaemia, temperature $>38^{\circ} \mathrm{C}$, respiratory insufficiency or those having any sort of infection are not included in the study.

Group I consisted of 500 cases who were given Inj. Ceftriaxone 1 gm IV after clamping the umbilical cord during caesarean section.

Group II consisted of 500 cases who received Inj. Ampicillin $500 \mathrm{mg}$ and Inj. Gentamicin 80 mgs which was started 4-6 hrs. after surgery and was given BD for $48 \mathrm{hrs}$. Followed by oral Amoxicillin 500 mgs $6^{\text {th }}$ hourly for $72 \mathrm{hrs}$. and Gentamicin 80 mgs. IM BD for 5 days.

The presence of temperature, vaginal infection, urinary tract infection, respiratory tract infection, abdominal wound infection, need for additional antibiotic, febrile morbidity and the period of hospital stay were carefully noted. High vaginal swab and abdominal wound swab were sent for culture and sensitivity and results on each group were meticulously compared.

\section{RESULTS}

Total no. of cases taken for Group I: 500

Total no. of cases taken for Group II: 500

\begin{tabular}{|c|c|c|c|c|}
\hline \multirow{2}{*}{ AGE GROUP } & \multicolumn{2}{|c|}{ GROUP I } & \multicolumn{2}{c|}{ GROUP II } \\
\cline { 2 - 5 } & No. & $\mathbf{\%}$ & No. & \% \\
\hline 16-25 yrs. & 435 & 87 & 422 & 84.4 \\
\hline $26-30$ yrs. & 57 & 11.4 & 67 & 13.4 \\
\hline 31 \& above & 8 & 1.6 & 11 & 2.2 \\
\hline Table 1: Age Distribution in Lower Segment \\
Caesarean Section Group \\
\hline
\end{tabular}

\begin{tabular}{|c|c|c|c|c|}
\hline \multirow{2}{*}{ PARITY GROUP } & \multicolumn{2}{|c|}{ GROUP I } & \multicolumn{2}{c|}{ GROUP II } \\
\cline { 2 - 5 } & No. & $\mathbf{\%}$ & No. & \% \\
\hline PRIMI & 232 & 46.4 & 243 & 48.6 \\
\hline MULTI & 268 & 53.6 & 257 & 51.4 \\
\hline \multicolumn{4}{|c|}{ Table 2} \\
\hline
\end{tabular}

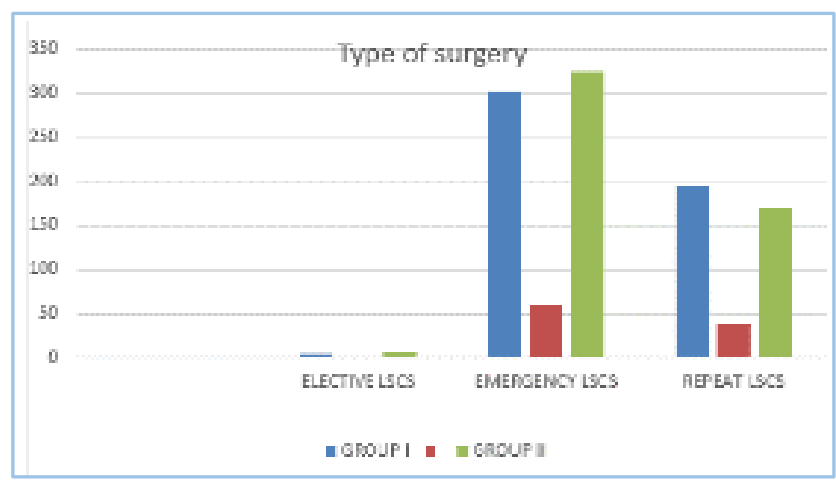

Fig. 1: Type of Surgery

\begin{tabular}{|c|c|c|c|c|}
\hline \multirow{2}{*}{ INDICATION } & \multicolumn{2}{|c|}{ GROUP I } & \multicolumn{2}{c|}{ GROUP II } \\
\cline { 2 - 5 } & No. & $\mathbf{\%}$ & No. & $\mathbf{\%}$ \\
\hline $\begin{array}{c}\text { Previous lower segment } \\
\text { caesarean section with CPD }\end{array}$ & 197 & 39.4 & 166 & 33.2 \\
\hline Fetal distress & 81 & 16.2 & 83 & 16.6 \\
\hline Failed induction & 28 & 5.6 & 44 & 8.8 \\
\hline Breech & 32 & 6.4 & 34 & 6.8 \\
\hline CPD & 53 & 10.6 & 54 & 10.8 \\
\hline Oligohydramnios & 24 & 4.8 & 17 & 3.4 \\
\hline
\end{tabular}

\begin{tabular}{|c|c|c|c|c|}
\hline Malpresentation & 2 & 0.4 & 2 & 0.4 \\
\hline BOH & 11 & 2.2 & 7 & 1.4 \\
\hline Others & 72 & 14.4 & 93 & 18.6 \\
\hline Table 3: Indications of Lower Segment Caesarean \\
Section
\end{tabular}

\begin{tabular}{|c|c|c|c|c|}
\hline \multirow{2}{*}{ BLOOD LOSS } & \multicolumn{2}{|c|}{ GROUP I } & \multicolumn{2}{c|}{ GROUP II } \\
\cline { 2 - 5 } & No. & $\mathbf{\%}$ & No. & \% \\
\hline $500-750 \mathrm{ML}$ & 300 & 60 & 360 & 72 \\
\hline $750-1000 \mathrm{ML}$ & 200 & 40 & 140 & 28 \\
\hline$>1000 \mathrm{ML}$ & - & - & - & - \\
\hline \multicolumn{3}{|c|}{$\begin{array}{r}\text { Table 4: Blood Loss During Lower } \\
\text { Segment Caesarean Section }\end{array}$} \\
\hline
\end{tabular}

\begin{tabular}{|c|c|c|c|c|}
\hline & \multicolumn{2}{|c|}{ GROUP I } & \multicolumn{2}{c|}{ GROUP II } \\
\cline { 2 - 5 } & No. & $\mathbf{\%}$ & No. & $\mathbf{\%}$ \\
\hline Temperature & 20 & 4 & 51 & 10.2 \\
\hline Cough & 4 & 0.8 & 10 & 2 \\
\hline Vomiting & & & 20 & 4 \\
\hline Abdominal distension & & & 10 & 2 \\
\hline Wound infection & 9 & 1.8 & 41 & 8.2 \\
\hline UTI & 10 & 2 & 33 & 6.6 \\
\hline Adverse reactions & & & 10 & 2 \\
\hline Abdominal wound resuturing & & & 5 & 1 \\
\hline Thrombophlebitis & \multicolumn{5}{|l}{} \\
\hline Table 5: Post-Operative Complications \\
\hline
\end{tabular}

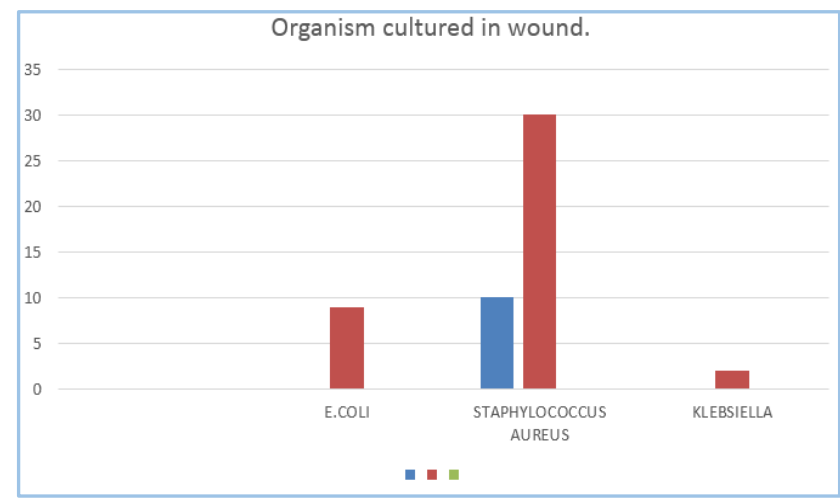

Fig. 2: Wound Infection

\begin{tabular}{|c|c|c|}
\hline ORGANISMS CULTURED & GROUP I & GROUP II \\
\hline E. coli & 10 & 28 \\
\hline Staphylococcus aureus & - & - \\
\hline Klebsiella & - & 4 \\
\hline Proteus & - & 1 \\
\hline \multicolumn{2}{|c|}{ Table 6: Urinary Tract Infection } \\
\hline
\end{tabular}

\begin{tabular}{|c|c|c|c|}
\hline RESULTS & GROUP-I & GROUP-II & P-VALUE \\
\hline Febrile morbidity & 4 & 10.2 & $<0.001$ \\
\hline Wound infection & 1.8 & 8.2 & $<0.001$ \\
\hline $\begin{array}{c}\text { Urinary tract } \\
\text { infection }\end{array}$ & 2 & 6.6 & $<0.001$ \\
\hline $\begin{array}{c}\text { Abnormal vaginal } \\
\text { discharge }\end{array}$ & - & 2 & $\begin{array}{c}\text { Not } \\
\text { Significant }\end{array}$ \\
\hline \multicolumn{3}{|c|}{ Table 7: Infectious Morbidity } \\
\hline
\end{tabular}

\begin{tabular}{|c|c|c|}
\hline \multirow{2}{*}{ POST-OP PERIOD } & \multicolumn{2}{|c|}{ No. of Days of Hospital Stay } \\
\cline { 2 - 3 } & Group I & Group II \\
\hline Afebrile patients & $\mathbf{9}$ & $\mathbf{9}$ \\
\hline Febrile patients & 12 & 15 \\
\hline Wound infection & 14 & 16 \\
\hline UTI & 10 & 12 \\
\hline \multicolumn{2}{|c|}{ Table 8: Postoperative Period } \\
\hline
\end{tabular}




\section{DISCUSSION}

The primary aim of prophylactic antibiotics is to reduce the infection and thereby reduce morbidity and mortality.(4) Antibiotic prophylaxis for caesarean should be perioperative ensuring a high plasma concentration of the antibiotics during lower segment caesarean section.(5),(6),(7) Various recent studies in obstetric cases proved that there is definite role of prophylactic antibiotics.(8),(9) Before the routine use of prophylactic antibiotics for caesarean section, the febrile morbidity and endomyometritis rates were $36 \%$ and $32 \%$ respectively.(10)

\begin{tabular}{|c|c|c|}
\hline & GROUP I $\mathbf{~ \%}\}$ & GROUP II $\mathbf{~ \%}\}$ \\
\hline Kristenson 1990 & 2 & 19.2 \\
\hline Saltzmann 1985 & 14 & 32.7 \\
\hline Itskovitz J 1979 & 16 & 30 \\
\hline Huam 1997 & 8 & 18 \\
\hline Bagratee 2001 & 8.3 & 7.9 \\
\hline Mancuso 1989 & 8 & 9.6 \\
\hline Sulovic 1994 & 12.5 & 24.2 \\
\hline Study Group & 4 & 10.2 \\
\hline \multicolumn{2}{|c|}{ Table 9: Febrile Morbidity } \\
\hline
\end{tabular}

In the present study, febrile morbidity was $4 \%$ in Ceftriaxone group when compared to $10.2 \%$ in conventional agents in Group II.

\begin{tabular}{|c|c|c|}
\hline & GROUP I & GROUP II \\
\hline Huam 1997 & 3 & 13 \\
\hline Bagratee 2001 & 12.5 & 13.3 \\
\hline Mallaret 1990 & 12.5 & 26 \\
\hline M. K. Swamy 1998 & 4 & 16 \\
\hline Brar et al. & 8 & 28 \\
\hline Study Group & 1.8 & 8.2 \\
\hline \multicolumn{2}{|c|}{ Table 10: Wound Infection } \\
\hline
\end{tabular}

In Group I, 9 patients developed wound infection, 6 patients on $6^{\text {th }}$ postoperative day and 4 on $7^{\text {th }}$ postoperative day and culture showed growth of staphylococcus aureus sensitive to ciprofloxacin. In Group II, 41 patients developed wound infection; 19 patients had growth of staphylococcus aureus sensitive to ciprofloxacin, 4 patients had E. coli and other patient had Klebsiella sensitive to Norfloxacin.

\begin{tabular}{|c|c|c|}
\hline & GROUP I & GROUP II \\
\hline Agarwal 1997 & NIL & 6 \\
\hline Batra 1994 & 4 & 8 \\
\hline M. K. Swamy 1998 & 2 & 22 \\
\hline Brar et al. & 12 & 32 \\
\hline Study Group & 2 & 6.6 \\
\hline \multicolumn{2}{|c|}{ Table 11: Urinary Tract Infection } \\
\hline
\end{tabular}

\begin{tabular}{|c|c|c|}
\hline & GROUP I & GROUP II \\
\hline Batra 1994 & NIL & 4 \\
\hline Brar et al. 1999 & NIL & 8 \\
\hline Samal 1988 & 2 & 2 \\
\hline M. K. Swamy 1998 & 1 & 15 \\
\hline Study Group & NIL & 2 \\
\hline \multicolumn{2}{|c|}{ Table 12: Adverse Reactions } \\
\hline
\end{tabular}

In Group II, 10 patients had diarrhoea for two days. In these cases Ampicillin was omitted and Ciprofloxacin started. In the present study, single dose use of Ceftriaxone has been documented to be more effective in controlling tissue inflammatory response.
Ceftriaxone is well tolerated after IV injection and has added advantage of better safety profile. Lower infection rates can be achieved using long acting antibiotics, such as ceftriaxone given as a single dose $(1 \mathrm{gm})$. The above findings are correlating with the current recommendation by Society of Obstetricians and Gynaecologists of Canada Infectious Diseases Committee, all women undergoing elective or emergency Caesarean section should receive antibiotic prophylaxis. (I-A). The choice of antibiotic for Caesarean section should be a single dose of a first-generation cephalosporin.(11)

\section{SUMMARY}

1. 500 cases of LOWER SEGMENT CAESAREAN SECTION were included in Group I and these were given Inj. Ceftriaxone $1 \mathrm{gm}$ IV after clamping umbilical cord.

2. 500 cases of LOWER SEGMENT CAESAREAN SECTION were included in Group II and they were given Ampicillin 500 mgs BD and II Inj. Gentamicin 80 mgs BD for 5 days as in present practice.

3. Incidence of febrile morbidity in Ceftriaxone group was $4 \%$ and Ampicillin/Gentamicin group was $10.2 \%$ with P-value of $<0.001$.

4. Incidence of wound infection in Ceftriaxone group was $1.8 \%$ and in Ampicillin/Gentamicin group was $8.2 \%$ with P-value $<0.001$.

5. Culture and sensitivity of pus from wound shows the growth of staphylococcus aureus in Ceftriaxone group was $1.8 \%$ and Ampicilliin/Gentamicin group was $8.2 \%$.

6. Incidence of UTI in Ceftriaxone group was $2 \%$ and Ampicillin/Gentamicin group was $6.6 \%$ and the organisms responsible for UTI were E. coli in Group I. In Group II E. coli, Klebsiella and Proteus and appropriate antibiotics like Ciprofloxacin started.

7. Incidence of adverse reactions were nil in Ceftriaxone group and Ampicillin/Gentamicin group were $2 \%$.

8. Overall, mean postoperative hospital stay was significantly less in Ceftriaxone group than Ampicillin/Gentamicin group.

9. Single dose Ceftriaxone prophylaxis is cost effective, in that the cost of treatment is 4 times less than that of conventional antibiotics Ampicillin/Gentamicin.

10. Ceftriaxone prophylaxis is safe, effective and convenient and saves man power, thus preventing irregularity in administering drugs and can easily replace the 5 days extended use of antibiotics.

\section{CONCLUSION}

In the present study, antibiotic prophylaxis with single dose ceftriaxone $1 \mathrm{gm} \mathrm{IV} \mathrm{administered} \mathrm{after} \mathrm{umbilical} \mathrm{cord}$ clamping in caesarean section is very safe, cost effective, more convenient and also effective in reducing maternal morbidity and post-operative hospital stay when compared to traditional use of Ampicillin/Gentamicin in caesarean section.

\section{REFERENCES}

1. Gordon HR, Phelps D, Blanchard K. Prophylactic cesarean section antibiotics: maternal and neonatal morbidity before or after cord clamping. Obstet Gynecol 1973;53(2):151-6. 
2. Kovitz J, Paldi E, Katz M. The effect of prophylactic antibiotics on febrile morbidity following cesarean section. Obstet Gynecol 1979;53(2):162-5.

3. Gall SA. The efficacy of prophylactic antibiotics in cesarean section. AM J Obstet Gynecol 1979;134(5):50611.

4. Schulze G. Prophylactic antibiotics in cesarean section. Zentralblatt Für Gynäkologie 1980;102(12):659-63.

5. Hawrylyshyn PA, Berustein P, Papsin FR. Risk factors associated with infection following cesarean section. AM J Obstet Gynecol 1981;139(3):294-8.

6. Padilla SL, Spence MR, Beauchamp PJ. Single dose ampicillin for cesarean section prophylaxis. Obstet Gynecol 1983;61(4):463-6.

7. Saltzmann DH, Eron LJ, Kay HH, et al. Single dose antibiotic prophylaxis in high risk patients undergoing cesarean section. Obstet Gynecol 1985;65(5):655-7.
8. Sulovic V, Ljubic A, Cvetkovic M, et al. Ceftriaxone in prevention of complications after cesarean section and its influence on the newborn. Clin Exp obstet gynecol 1994;21(1):33-7.

9. Huam SH, Lim JM, Raman. Single dose antibiotic prophylaxis in women undergoing elective cesarean section. Med J malaysia 1997;52(1):3-7.

10. Bagratee JS, Moodley J, Kleinschmidt I, et al. A randomized trial of antibiotic prophylaxis in elective cesarean section. BJOJ 2002;109(12):1423-4.

11. Van Schalkwyk J, Van Eyk N. Antibiotic prophylaxis in obstetric procedures. Journal of Obstetrics and Gynaecology Canada 2010;32(9):878-92. 